\title{
Ressignificando o brincar através da prática docente na educação infantil: a criança como sujeito de direito
}

\section{Ressignifying play through teaching practice in early childhood education: the child as a subject of law}

Magali Dias da Conceição Machado ${ }^{1 *}$, José Carlos de Melo $^{1}$, Suzane Castro de Araújo Silva ${ }^{1}$

\section{RESUMO}

Este artigo tem como objetivo refletir sobre o papel do educador considerando o percurso histórico da criança e do brincar. Utilizou-se os pressupostos teóricos advindos de Vygotsky (1998)e Fröebel (1912) que trazem o brincar como atividade importante. Kuhlmann Jr (2010)., Kramer (1987), Ariès (2014) que traçam o caminho situando a criança e o brincar na história, além da legislação nacional que insere a educação infantil no cenário político e define o papel do educador. Assim, para compreender a relevância do objeto de estudo, é necessário problematizar as concepções de criança e infância. Trata-se de uma pesquisa de revisão de literatura e de abordagem qualitativa, na qual foi possível compreendermos a criança como um sujeito de direito, entender a evolução das concepções do brincar e também o percurso histórico no intuito de garantir o brincar como um direito da infância e o papel do educador nessa garantia dentro dos espaços de Educação Infantil. Esperamos que essa investigação possa servir de reflexão que a criança aprende por meio da brincadeira, que o brincar deve ser oferecido ao longo de toda a etapa da educação infantil sendo papel do educador organizar tempos e espaços para que essa ação seja garantida.

Palavras-chave: Brincar; Prática Docente; Educação Infantil.

\begin{abstract}
This article aims to reflect on the role of the educator considering the historical path of children and playing. For that, it was supported by the theoretical assumptions coming from Vygotsky (1998) and Fröebel (1912) that bring playing as an important activity of childhood. Kuhlmann Jr. (2010), Kramer (1987), Ariès (2014) that trace the path by placing the child and playing in history, in addition to the national legislation that inserts early childhood education in the political scenario and defines the role of the educator. Thus, to understand the relevance of the object of study, it is necessary to problematize the conceptions of child and childhood. This is a literature review and qualitative approach research, in which it was possible to understand the child as a subject of rights, to understand the evolution of conceptions of playing and also the historical course in order to guarantee playing as a right of childhood and the role of the educator in this guarantee within the spaces of Early Childhood Education. We hope that this investigation can serve as a reflection that the child learns through playing, and that it should be offered throughout the entire stage of early childhood education, and the educator's role is to organize times and spaces so that this action is guaranteed.
\end{abstract}

Keywords: Playin; Teaching Practice; Child education.

\footnotetext{
${ }^{1}$ Universidade Federal do Maranhão.

*E-mail: magali.dias@ discente.ufma.br
} 


\section{INTRODUÇÃO}

Figura 1 - Cabo de guerra

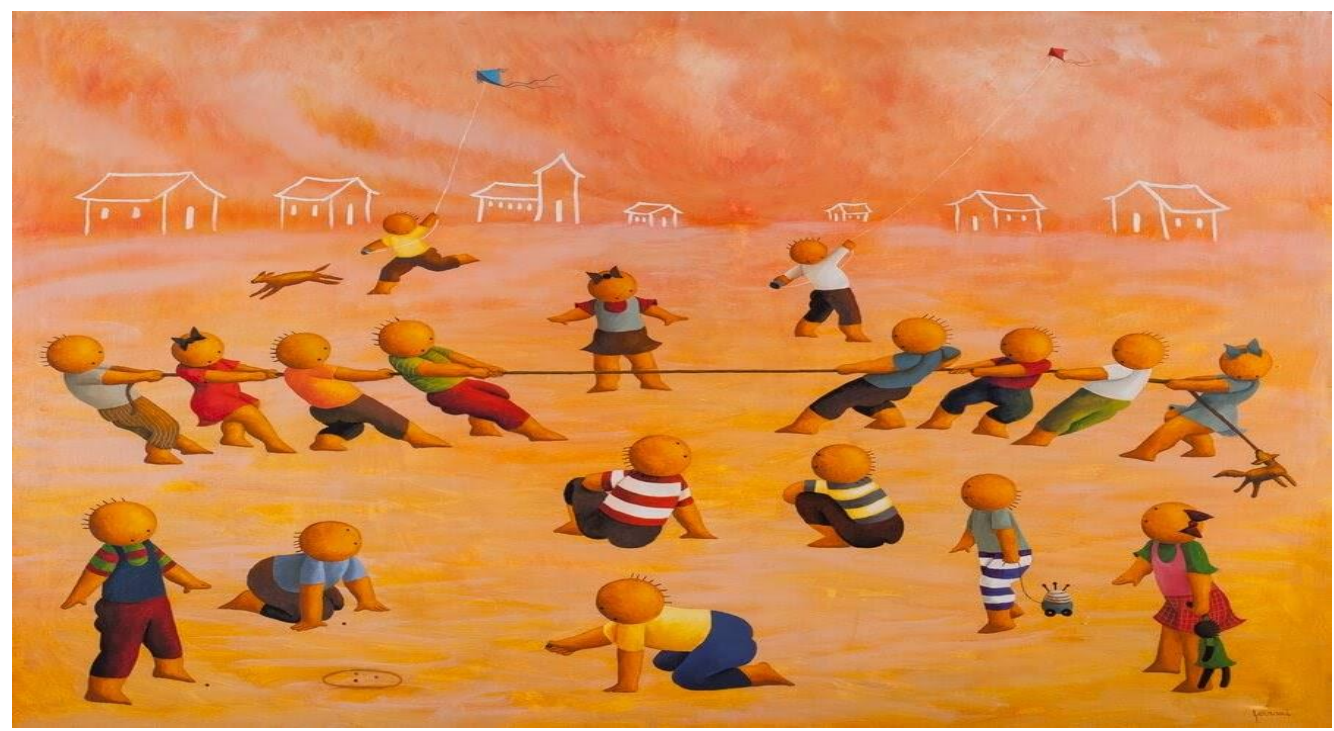

Fonte: Ricardo Ferrari (2011)

A pintura que ilustra essa introdução é de Ricardo Ferrari e nos faz um convite a embarcar nas nossas memórias e nos transportar para o tempo em que éramos crianças e foi escolhida por representar a concepção de um brincar de direito.

Ao pensar sobre a infância, Ferrari ilustra com saudosismo seu quintal, e os momentos de diversão ao lado dos amigos que se reuniam para brincar. Pensar em infância e criança é pensar no brincar e isso faz parte dessa etapa da vida, é o exercício e o trabalho da criança.

As reflexões realizadas sobre o brincar infantil, estão traduzidas nessa imagem, o brincar livre, interações com a natureza e com outros parceiros, livre de obrigatoriedade, com espaços significativos e criativos, de tal modo que o brincar esteja presente nas rotinas infantis tanto fora quanto dentro das instituições educativas.

Valorizar o brincar como atividade principal dentro dos espaços de Educação Infantil é um dos pontos de partida para reconhecer a criança como sujeito de direito. A criança que brinca mediada por um adulto é capaz de construir conhecimento e desenvolver habilidades primordiais para a vida presente e futura.

Desde a Declaração Universal dos Direitos Humanos (ONU,1948) até os documentos nacionais que norteiam a Educação Infantil, fazendo referência ao mais recente, a Base Nacional Comum Curricular (BNCC) (BRASIL, 2018), o brincar está 
associado ao lazer, recreação e assegurado como um dos principais direitos da aprendizagem e do desenvolvimento infantil.

Compreender a criança por meio de sua atividade principal é algo que se caracteriza como uma possibilidade muito complexa. Embora os avanços dos estudos e produções acadêmicas nessa área tenham ganhado grandes proporções, o brincar ainda é visto como ferramenta auxiliadora no processo de consolidação de conteúdo, entendido como recurso didático e em outros casos como atividade de passatempo.

Assim, tomando como base o brincar enquanto direito social e educacional da criança, é interessante refletir sobre os motivos que levam algumas instituições de Educação Infantil e educadores a restringirem ou reprimirem o brincar, em detrimento de atividades escolarizadas que antecipam conteúdos relacionados ao ensino fundamental infringindo um direito essencial da criança de aprender pela brincadeira.

De tal modo, percebendo que a realidade na Educação Infantil, ainda ignora em sua rotina o brincar como atividade relevante, faz-se necessário, pensar também nas práticas pedagógicas do educador que foram se transformando conforme os avanços nos debates sobre a regulamentação da educação infantil.

Dessa maneira, como forma de assegurar o direito da criança de brincar, o educador entra como ferramenta essencial para que as práticas lúdicas e de aprendizagem ocorram nesses espaços de Educação Infantil. Sabemos que para assumir esse papel, o educador precisa refletir sobre a importância do brincar e suas contribuições para a aprendizagem infantil.

A criança não brinca sozinha, de modo que o brincar é considerado uma atividade social e cultural. Assim, para que essa atividade ocorra plenamente, é necessário a presença de algo ou alguém para conduzir essa relação, ao passo que conviver com o outro e interagir na brincadeira é o caminho para a aprendizagem infantil.

Assim, o presente estudo se constitui num incentivo aos educadores a conhecerem a trajetória da criança enquanto sujeito de direito trazendo o brincar como ferramenta importante para a formação infantil. Dessa forma, buscou-se entender e analisar como o brincar pode orientar a prática docente do educador de modo a garantir o direito da criança de se desenvolver integralmente nas instituições de Educação Infantil.

Para subsidiar o entendimento acerca das concepções de criança e brincar que permeiam a Educação Infantil, optou-se por uma pesquisa do tipo bibliográfica por 
objetivar realizar uma revisão de obras já publicadas e uma abordagem qualitativa por ter o objetivo de produzir informações aprofundadas e ilustrativas.

Deste modo, o presente artigo estará organizado em seis seções, sendo a primeira apresentado na introdução o contexto a ser estudado, seguido da metodologia utilizada para elaboração deste estudo, na terceira os aspectos históricos relacionados a criança e o brincar. Em continuidade, a quarta seção faz-se importante trazer o lugar do brincar na legislação brasileira tencionando justificar por que o brincar deve permear toda a prática docente. A quinta seção discorre sobre o papel do educador na ressignificação do brincar dentro do contexto da educação infantil. E finalizando, apresentamos algumas considerações em relação ao papel do educador frente a defesa da criança enquanto sujeito de direito tendo no brincar a principal ferramenta auxiliadora do seu trabalho docente.

Espera-se que este estudo contribua para a ressignificação do olhar do brincar na educação infantil possibilitando aos educadores refletir sobre sua prática docente.

\section{METODOLOGIA}

Neste trabalho de ressignificar o brincar através da prática docente na Educação Infantil, podemos compreender que é uma atividade que faz parte da infância e que legitima direitos as crianças de poder se desenvolver por meio dela. Os educadores tem a missão de garantir isso nos espaços de interação escolar, assim por meio de sua prática proporcionar e facilitar experiências que permitam a criança brincar e se desenvolver brincando.

Na elaboração deste artigo no que se refere a natureza é do tipo aplicada, pois visa possibilidades de produção de conhecimento (PERREIRA, 2019, p. 26). A centralidade da abordagem é qualitativa pois utiliza o significado e toda uma descrição dos conceitos de brincar e infância ao longo da construção histórica dos conceitos bem como os ganhos com relação ao direito legal do brincar.

Quanto aos instrumentos de geração de dados foram utilizados a análise dos documentos oficiais, legislações, livros e outros para comparar, perceber e descrever a concepção do brincar, de infância e a importância de uma prática docente que tem como ponto central o brincar no desenvolvimento pleno das crianças. Fonseca (2002, p. 32) diz que "a pesquisa bibliográfica é feita a partir do levantamento de referências teóricas já analisadas, e publicadas por meios escritos e eletrônicos" 
Com relação aos objetivos, a pesquisa é do tipo explicativa pois parte do uso da pesquisa bibliográfica que procura explicar e discutir um tema com base em referenciais teóricos. Este tipo de pesquisa tem como finalidade colocar o pesquisador em contato direto com tudo o que foi escrito, dito ou filmado sobre determinado assunto (MARCONI e LAKATOS, 2007).

Assim, a importância da pesquisa bibliográfica está diretamente ligada a este artigo assim como está ligada ao processo de investigação. Prodanov e Freitas (2013, p. 78) resumem essa importância ao dizer que "a revisão de literatura tem papel fundamental no trabalho acadêmico, pois é através dela que você situa seu trabalho dentro da grande área de pesquisa da qual faz parte, contextualizando-o".

\section{A CRIANÇA E O BRINCAR: aspectos históricos}

Nas Diretrizes Curriculares Nacionais da Educação Infantil (DCNEI) (BRASIL, 2010) a concepção de criança que temos hoje é como sujeito histórico e de direitos, que aprende e desenvolve no processo das interações sociais, na qual demorou um longo percurso para ser considerado, assim aconteceu com o brincar infantil, um largo caminho para ser compreendido como atividade importante da criança que caracteriza o cotidiano de sua infância conforme consta na Base Nacional Comum Curricular (BNCC) (BRASIL, 2018).

Dessa forma, para compreender os motivos que levaram a criança a si torna um sujeito de direito, torna-se necessário primeiramente, conhecer a evolução dos conceitos de criança e de infância, assim como o de brincar, dentro de um contexto histórico.

A história da criança e do brincar andam lado a lado em termos de reconhecimento e valorização. Ao pesquisar a história do brincar, Wajskop (1995) diz que na antiguidade tanto as crianças quanto os adultos participavam dos mesmos ritos e brincadeiras sem distinção de idades na justificativa de estreitar laços coletivos.

As brincadeiras prevaleciam apenas na primeira infância, que naquela época correspondia até a idade dos quatros anos. A criança nesse período era representada como uma miniatura do adulto, um ser biológico sem autonomia, sem representação e inserida numa sociedade autocêntrica. Ela se juntava aos adultos logo nos primeiros anos de vida, 
sem haver uma transição para isso, ou respeito pela distinção das idades (ARIÈS, 2014, p. 99)

Por muito tempo o sentimento de indiferença com a criança e sua infância persistiu nas sociedades antigas. Ariès (2014) retrata que até a morte de uma criança era tratado com indiferença, "a criança era tão insignificante, tão mal entrada na vida, que não se temia que após a morte ela voltasse para importunar os vivos" (ARIÈS, 2014, p. 22), denotando a ideia de ser sem valor.

Nesse mesmo período, as brincadeiras eram vistas apenas na primeira fase da infância, onde com ajuda dos escritos de Ariès (2014), ele narra como essa criança pequena brincava com as bonecas e ao mesmo tempo participava de atividades de jogos os com adultos. Ao passo que assim que se distanciava dos primeiros anos de vida, era induzido a abandonar a brincadeira, vista como ocupação, passando a ser uma pessoa grande e não mais uma criança.

Com a descoberta do sentimento da infância, nasce a consciência da particularidade infantil diferenciando a criança do adulto e a valorização da brincadeira. No livro "História Social da Criança e da Família" Ariès (2014) coloca que os jogos e as brincadeiras passaram por um período de transição ora aceito por alguns, ora condenado por outros, como os moralistas e a igreja, que associavam as brincadeiras aos prazeres carnais, ao vício e ao azar.

Durante o período do Renascimento, os jogos ganham valor e na escola tinham a finalidade de ser um recurso auxiliar do ensino, resumido a estratégia, e técnica que objetivava o ensino. Já com os estudos de Rousseau (2004) o brincar passa a ser considerado como ocupação principal da criança e o fio condutor para a aprendizagem, mesmo que de maneira restrita.

A criança passa a ser aceita e preservada por sua ingenuidade natural dando abertura para as discussões acerca de uma nova concepção de infância e como educá-la para além de um regime sério e controlador, imposto pelas escolas.

Dos estudos de Fröebel (1912) surge a preocupação com as necessidades individuais das crianças e a valorização dos jogos ganha terreno enquanto atividade própria delas. $\mathrm{O}$ autor traz contribuições acerca desta temática, a primeira quando afirma que a brincadeira é importante para o desenvolvimento da criança e a insere em sua proposta pedagógica por entender que por meio das brincadeiras pode-se ensinar a linguagem à criança. A segunda quando afirma que "nas brincadeiras a criança tenta 
compreender seu mundo e reproduzir situações da vida" criando significações simbólicas a partir de objetos da cultura.

Vygotsky (1998), concordando com os pensamentos de Fröebel (1912), relata sobre a importância do brincar, considera essa ação como atividade principal da criança pequena por favorecer seu desenvolvimento integral. Essa atividade principal é aquela em conexão com a qual ocorrem as mais importantes transformações no desenvolvimento psíquico da criança e dentro da qual se desenvolvem processos psíquicos que preparam o caminho da transição da criança para um novo e mais elevado nível de desenvolvimento.

Numa perspectiva de considerar o brincar como direito da criança, especialmente nos primeiros anos de vida e dentro das instituições de Educação Infantil, Vygotsky (1998) compreende que a criança é um ser que aprende a partir da interação com o meio social e o brincar como atividade principal.

Com relação ao brincar e o desenvolvimento da criança, Vygotsky (1998) coloca que é durante a brincadeira que são construídas zonas de desenvolvimento proximal (ZDP) onde, com a ajuda de outra pessoa mais velha ou mais experiente, a criança alcança um nível de desenvolvimento, ou seja, a partir do que ela já consegue fazer por si mesma e também com ajuda do outro. Na brincadeira a criança tem a oportunidade de ser aquilo que ainda não é, agindo como se ela fosse maior do que é, podendo usar e saber de coisas que ainda não lhes são permitidas.

Assim, para Vygotsky (1998) a criança quando brinca interpreta e compreende as relações do mundo do adulto, experimentando-o sem perder sua essência infantil sendo maior do que a realidade. Por isso, enquanto brinca, a criança desenvolve sua imaginação e transforma suas relações tomando consciência da realidade e dos significados culturais do meio em que está inserida.

A criança, segundo Vygotsky (1998), brinca para aprender a elaborar e resolver situações conflitantes que vivencia no seu dia a dia e ao reproduzir comportamentos sociais do adulto quando brinca, a criança estará combinando situações reais com elementos da sua imaginação. Deste modo, ela estará interagindo com o mundo se constituindo como agentes de sua experiência cultural como afirma Borba $(2009$, p. 70 e 71)

Ao brincar a criança não apenas expressa e comunica suas experiências, mas reelabora, reconhecendo-se como sujeito pertencendo a um grupo social e a um contexto social, aprendendo sobre si mesma e sobre os homens e suas relações no mundo, e também sobre os significados 
culturais do meio em que está inserida. O brincar é, portanto, experiência de cultura, por meio da qual valores, habilidades, conhecimentos e forma de participação social são constituídos e reinventados pela ação coletiva das crianças.

Assim, ao considerar o brincar como atividade principal da criança em idade pré-escolar, Leontiev (2001a p.121) colaborador de Vygotsky, afirma que é no decorrer do desenvolvimento mental das crianças que a atividade lúdica se torna a principal atividade e que a cada etapa do desenvolvimento infantil tem uma atividade guia, e que as crianças em idade pré-escolar essa atividade é a brincadeira.

O brincar satisfaz certas necessidades da criança e essas necessidades são distintas em cada fase infantil, pois vão mudando no decorrer de sua maturação. Por exemplo, o interesse de uma criança muito pequena ao brincar com um objeto, é diferente de uma criança maior. A partir do momento que as crianças vão passando a ter consciências dos artefatos culturais, ela sente a necessidade de agir sobre ele, manipulando conforme imita um adulto. Dessa forma, como ainda não é capaz de fazer sozinha, ela utiliza-se do brincar pelo aspecto livre, sem julgamentos, onde a criança passa a ser o que ela tem necessidade.

Portanto, colocar o brincar como atividade principal, não é tarefa fácil e requer que o educador tenha uma atitude lúdica e responsiva voltada para a real necessidade da criança.

Kishimoto (1998) em seu livro o brincar e suas teorias, aponta um estudo pautado nos pressupostos de Fröebel, onde o brincar é visto como algo altamente sério e de profunda significação, pois na brincadeira," a criança tenta compreender seu mundo ao reproduzir situações da vida". O brincar tem uma ligação direta com a criança, pois nos primeiros anos de vida, a brincadeira favorece o desenvolvimento da criança principalmente pelo caráter do desenvolvimento simbólico. (KISHIMOTO, 1998, p.68)

Para a autora o brincar nessa fase compreendido como a primeira infância, favorece a linguagem pela mediação do adulto e pelos objetos que são oferecidos. Pensar no brincar na educação infantil, é garantir o direito da criança através do respeito aos interesses da criança.

Contudo, a concepção de criança e do brincar foram evoluindo e sendo construídas conforme a história e o contexto social onde a criança era inserida. Atualmente, com uma definição bem consolidada, a criança se torna um ser de direitos e 
o brincar como direito social e educacional dessa criança. Nesse sentido, é importante entender a função social das instituições de Educação Infantil como um direito da criança.

\section{O LUGAR DO BRINCAR NA POLÍTICA NACIONAL DA EDUCAÇÃO INFANTIL}

O brincar é tão importante na vida da criança que se tornou direito previsto em lei. A Declaração Universal dos Direitos Humanos (ONU, 1948) em seu artigo 24 informa que toda pessoa tem direito ao lazer. Já a Declaração Universal dos Direitos da Criança (ONU, 1959), coloca em seu $7^{\circ}$ princípio, que a criança terá ampla oportunidade de brincar e divertir-se, cabendo à sociedade e às autoridades públicas promover e assegurar esse direito.

O Estatuto da Criança e do Adolescente (ECA) (BRASIL, 1990) trata desse direito ao garantir que a criança tenha direito a brincar e divertir-se. Nessa mesma direção, a Lei n 13.257/2016 (BRASIL, 2016), o Estatuto da Primeira Infância, assegura o brincar como uma das áreas prioritárias para as políticas públicas para a primeira infância. Porém, para compreender como o brincar chegou à categoria de direito no âmbito educacional, é preciso um breve resgate histórico.

Com a passagem do atendimento religioso para $\mathrm{o}$ atendimento assistencialista, surge uma maior preocupação com a criança e o reconhecimento dessa fase infantil como importante. Até antes da segunda metade do século XIX, não existia no Brasil uma preocupação para o atendimento de crianças menores de 6 anos, essa tarefa, era responsabilidade das famílias conforme estudo de Kuhlmann Jr. (2010)

$\mathrm{O}$ atendimento a infância passa a existir a partir de 1874 com as "rodas dos expostos" e outras instituições destinadas ao amparo da infância, todas destinadas ao atendimento da criança pobre e mais adiante ao atendimento dos filhos dos operários, onde uma das principais características era um atendimento de baixa qualidade e o controle intelectual das crianças.

Nesse contexto, surgem as creches e os jardins de infância idealizado por Fröebel (1912), que proporcionou a Educação Infantil a possibilidade de brincar, desconstruindo a ideia do brincar associado a corrupção infantil rompendo a concepção tradicionalista de criança passando a respeitá-la em sua inteireza e compreendê-la como 
ser ativo, vendo nas brincadeiras possibilidades de aprender e compreender o mundo, porém, esse modelo de educação não atendia as crianças pobres.

Entre as décadas de 60 e 70 o atendimento educacional da criança passa a ser visto como forma de melhorar a condição social das famílias pobres. Assim, às crianças de baixa renda eram destinadas a atividades de caráter social, motoras, com a finalidade de compensar e minimizar o fracasso escolar.

Dentro do cenário educacional e das políticas públicas, o brincar é inserido no Brasil com um movimento tardio na Educação Infantil. Os movimentos sociais foram em parte um dos principais responsáveis por redimensionar o olhar e o pensamento em relação à criança pequena.

Leis que garantiriam o acesso e a permanência da criança em instituições de Educação Infantil, só foram sendo contempladas no final da década de 80, com a Constituição Federal (BRASIL, 1988), a qual garantia a criança o direito a educação em creches e pré-escolas sendo de responsabilidade do Estado assumir esse papel.

Assim, com os avanços legais, as discussões sobre como organizar o trabalho com essas crianças, respeitando seus direitos e especificidades, ganham força. É com a promulgação dessas leis que as crianças passam a ser consideradas sujeitos de direito, produtoras de cultura e cidadãs. $\mathrm{O}$ atendimento educacional passa a ser um direito da criança e não mais um direito da mãe operária.

O direito a infância, ao brincar e ao não trabalho passa a ser observado e o caráter lúdico torna-se um componente relevante nesses espaços de educação. A criança passa a ser compreendida sob outra perspectiva, como afirma Benjamin (1984, p.11)

\footnotetext{
A criança não é uma miniatura do cosmos adulto; bem ao contrário, em ser humano de pouca idade que constrói seu próprio universo, capaz de incluir lances de pureza e ingenuidade, se eliminar, todavia a agressividade, resistência, perversidade, humor, vontade de domínio e de mando.
}

Perspectiva essa que legitima a criança como cidadã, perante a sociedade, também tem direitos e sua capacidade de desenvolvimento também é reconhecida sob a ótica de um ser ativo e em pleno desenvolvimento.

Em 1994 com a aprovação da primeira versão da Política Nacional de Educação Infantil (BRASIL, 2006a) diretrizes norteadoras direcionadas para o desenvolvimento da criança, foram enfatizando o brincar como modo privilegiado de aprendizagem e desenvolvimento infantil ampliando os espaços de direito da criança. 
Essa abertura para as discussões de melhorias na Educação Infantil, tendo o brincar como elemento fundamental para a aprendizagem infantil, foram ganhando força, chegando aos educadores que atuam nessa área.

Logo, em 1996, a Lei de Diretrizes e Bases da Educação Nacional (LDBEN) (BRASIL, 1996) foi promulgada, estabelecendo à Educação Infantil a primeira etapa da educação básica, definindo como finalidade a promoção do desenvolvimento integral da criança até seis anos de idades.

Os Referenciais Curriculares Nacionais para a Educação Infantil (RCNEI) (BRASIL,1998) direcionaram o trabalho educativo junto à criança pequena, trazendo a preocupação não somente com os cuidados essenciais, mas com o educar, trazendo as brincadeiras como atividade importante para o desenvolvimento integral da criança. Nesse documento o papel dos profissionais que cuidam e educam é de fundamental importância para a garantia de um desenvolvimento pleno durante a estadia da criança na etapa da Educação Infantil.

Em 2009, o documento "Critérios para um atendimento em creches que respeitem os direitos fundamentais das crianças", reconhece que a criança tem direito a brincadeira e a ampliação de seus conhecimentos. (CAMPOS, 2009)

Adiante, em 2010, as Diretrizes Curriculares Nacionais para a Educação Infantil (DCNEI) (BRASIL, 2010) elaboram normas para a garantia da continuidade do processo de aprendizagem e desenvolvimento da criança, apontando dois eixos norteadores para a organização do trabalho pedagógico: as interações e as brincadeiras.

Hoje, o brincar está inserido na categoria de prioridades da criança, por ser considerado essencial ao desenvolvimento infantil. Mesmo observando em algumas instituições e de forma equivocada a didatização das atividades lúdicas como aponta Wajskop (2001, p. 23) que a "maioria das escolas tem didatizado a atividade lúdica das crianças, restringindo-as a exercícios de discriminação viso motora e auditiva, através do uso de brinquedos, desenhos coloridos ou mimeografados e músicas rimadas".

$\mathrm{Na}$ consulta aos documentos que orientam a política nacional da educação infantil a que tivemos acesso, os termos brincadeira, lúdico e lazer se referem ao ato de brincar como fundamental e potencializadora do desenvolvimento integral da criança. Assim, nos atraiu saber, qual o papel do educador frente ao brincar como atividade principal e direito da criança, o que será objeto de estudo de aprofundamento na seção seguinte deste trabalho. 


\section{O BRINCAR COMO EIXO ESTRUTURANTE DA PRÁTICA DOCENTE}

Ao longo das nossas leituras podemos perceber que é relevante que o brincar tem sua devida importância no desenvolvimento infantil. O diálogo sobre o papel do brincar foi sendo construído ao passo que a criança e a infância foram sendo reconhecidas.

Hoje, é impossível pensar na criança sem associá-la ao brincar. Um brincar visto como direito, promovido em qualquer espaço que acolha a criança, principalmente nos espaços da Educação Infantil. Durante as brincadeiras, a criança interage com o mundo, consigo mesma e com os outros, construindo aprendizagens que favorecem o seu desenvolvimento, como salienta Kishimoto (2011, p.151)

É possível entender que o brincar auxilia a criança no processo de aprendizagem, proporcionando situações imaginárias em que ocorrerá no desenvolvimento cognitivo e facilitando a interação da criança com diferentes pessoas, as quais contribuirão para um acréscimo de conhecimentos.

Nesse contexto, a figura do adulto entra como agente mobilizador e mediador dessa ação, uma vez que a criança precisa dessa interação e de um ser mais experiente para que a aprendizagem aconteça aproximando das ideias de Vygotsky apud Borba (2009, p. 72) descreve

O brincar é compreendido pelo autor como uma atividade construída pela criança nas interações que estabelece com outros sujeitos e com os significados culturais do seu meio, ou seja, a criança aprende a brincar com a mãe, avó, o pai, avô, os irmãos, primos, educadores, enfim, com crianças e adultos em geral como os quais estabelece interações que assumem a dimensão lúdica da brincadeira.

No entanto, para que essa mediação aconteça de forma consciente e significativa, é necessário que o educador tenha clareza sobre o seu papel durante o brincar, pois no percurso histórico aponta que no contexto educacional das instituições de Educação Infantil, o papel do educador também sofreu bastante transformação até chegar nos modelos que temos hoje.

Antigamente a ação de cuidar e educar era tarefa exclusivamente das famílias, representada pela figura da mãe, que posteriormente com o surgimento das escolas, esse papel passou a ser de mulheres sem qualificação ou formação especializada, com o propósito apenas assistencialista de prover alimentação, cuidado e higiene. 
As funções do educador variavam de acordo com cada momento histórico da Educação Infantil, desde pajem, jardineira, tia, até educadora. De proteger e alimentar a criança, o educador passou a organizar ambientes para que a criança pudesse agir. Ultrapassando a ideia de ser visto como aquele que ensina transmitindo conhecimentos específicos até alcançar a figura de interlocutor e intelectual e que também aprende na interação com a criança.

Para o atendimento nas instituições de Educação Infantil, não existiam critérios legais para trabalhar com crianças pequenas. Creches e pré-escolas se diferenciavam pelo atendimento e pelos profissionais. Nas Creches os atendimentos eram realizados por médicos, assistentes sociais e auxiliares, sem qualificação para atender a classe popular. As pré-escolas destinadas ao atendimento da elite, especialmente feito pelos professores, em especialmente as normalistas influenciando nesse momento a questão profissional.

Até a década de 70 o modelo médico-higienista de atendimento às crianças menores de seis anos prevalecia. A ausência de apoio do Estado ainda era forte e o caráter de caridade prevalecia, justificando a precariedade dos profissionais que atendiam as crianças. As propostas educativas para as crianças eram pautadas em atividades estereotipadas e de treino motor. A partir dessa década, a preocupação com o caráter mais educacional e menos assistencialista começa a aparecer no cenário político (KRAMER, 1987) e as funções e os métodos pedagógicos que norteariam a Educação Infantil passam a ser discutidos.

As primeiras experiências de formação de professores, datam a partir do período republicano, um avanço bastante significativo, mas ainda sem o reconhecimento do Estado. Assim, ao passo que a discussão sobre a criança e o brincar foram avançando, as discussões acerca de quem seria a responsabilidade de cuidar e educar também foram sendo ampliadas.

Como a abertura dos debates envolvendo a melhoria da qualidade na Educação Infantil, surge a preocupação com a formação profissional daqueles que atuam nessa etapa. Em 1971, a Lei n 4.024/61 (BRASIL, 1961) regulamenta a formação do professor de pré-escola no curso de magistério do $2^{\mathrm{o}}$ grau na forma de uma $4^{\mathrm{a}}$ série após os 3 anos de formação do magistério. Mais tarde, a Lei 9. 394/96 (LDB) (BRASIL, 1996) em seu artigo 62 apresenta uma importante exigência para aqueles que trabalham com criança pequena 
A formação de docentes para atuar na educação básica far-se-á em nível superior, em curso de licenciatura plena, admitida, como formação mínima para o exercício do magistério na educação infantil e nos cinco primeiros anos do ensino fundamental, a oferecida em nível médio, na modalidade normal.

Com essa exigência, o papel e a função do educador infantil ficaram mais claro, valorizando o profissional e garantindo à criança o direito de ser vista como ser de importância. Dessa forma, o educador começa a perceber que precisa conhecer as especificidades dessa etapa e entender os benefícios que a atividade do brincar reserva à criança.

Em 1998, os Referenciais Curriculares Nacionais para a Educação Infantil (RCNEI) (BRASIL,1998), assumem as funções social, cultural e política, garantindo a construção do conhecimento através das interações sociais. Este documento defende o brincar como atividade fundamental na rotina escolar e coloca o educador como mediador desse processo, sendo responsável por planejar sua prática educativa de forma que promova a aprendizagem da criança.

Ao observar e brincar com as crianças, o educador compreende a importância dessa atividade para a aprendizagem infantil ao verificar o esforço que a criança faz ao compreender o mundo através da brincadeira, "é por meio das brincadeiras que os professores podem observar e construir uma visão dos processos de desenvolvimento da criança [...]” (BRASIL, 1998, p. 28)

É importante que o educador, conheça não somente os aspectos do desenvolvimento infantil, mas a história da Educação Infantil e os processos que levaram para a concepção de criança, brincar, Educação Infantil que temos hoje. Dessa forma, seu processo de organização das propostas e de rotinas não ficarão confusas ou inseguras diante das brincadeiras, pois essa insegurança se reflete na ausência de uma identidade profissional em relação as concepções adotadas. Assim o educador que está envolvido diretamente nesse processo de brincar e aprender precisa refletir e ter ações práticas para que possam auxiliar a criança a vivenciar esse período e que assegure o direito a brincar.

O brincar deve ganhar espaço dentro das instituições de educação infantil. Porto e Cruz (2004, p. 32), destaca que seria interessante que os cursos de formação inicial possibilitassem um contato mais sério com a brincadeira pela importância que essa atividade tem para o desenvolvimento da criança. 
É essencial que isso seja feito de forma vivencial para que os professores possam dá-se conta, por intermédio de suas mãos, dos seus olhos, dos seus ouvidos, do seu corpo, dos seus valores morais e educativos, que o brinquedo é importante para que a criança possa desenvolver-se, tendo um rico contributo não só no aspeto psicológico, como sociocultural e, ainda, no aspecto pedagógico. Por isso é necessário que, além de conhecer o significado do brinquedo, o professor brinque.

Assim, as Diretrizes Curriculares Nacionais da Educação Infantil (DCNEI) (BRASIL, 2010) apontam que a orientação do trabalho junto à criança precisa ganhar status de prioridade. $\mathrm{O}$ documento entende que as práticas pedagógicas devem estar voltadas para as experiências e saberes infantis. Ao passo que privar a criança das brincadeiras é ignorar seus conhecimentos prévios e desrespeitar seus direitos. Além disso, o documento destaca as brincadeiras como um dos eixos norteadores da prática docente. Nesse sentido, as brincadeiras devem ser consideradas como atividade principal e como proposta de organização do planejamento.

Corroborando com as Diretrizes a criança e o brincar ganham um maior espaço dentro da Base Nacional Comum Curricular (BNCC) (BRASIL, 2018) que investe no brincar trazendo-o como direito de aprendizagem e desenvolvimento, complementando que "a interação durante o brincar caracteriza o cotidiano da infância, trazendo consigo muitas aprendizagem e potenciais para o desenvolvimento integral das crianças" (BRASIL, 2018, p. 37).

Ao educador cabe organizar situações de aprendizagem de modo intencional tendo como referência o brincar. No texto introdutório da BNCC (BRASIL, 2018, p. 34) a intencionalidade educativa entra como:

Essa intencionalidade consiste na organização e proposição, pelo educador, de experiências que permitam às crianças conhecer a si e ao outro e de conhecer e compreender as relações com a natureza, com a cultura e com a produção científica, que se traduzem nas práticas de cuidados pessoais (alimentar-se, vestir-se, higienizar-se), nas brincadeiras, nas experimentações com materiais variados, na aproximação com a literatura e no encontro com as pessoas.

Quando o educador pensa na organização dos espaços e das rotinas na Educação Infantil, tendo o brincar como eixo estruturante, ele está assegurando um direito essencial da criança, respeitando a infância, além de promover seu desenvolvimento. Nessas interações, o educador estreita laços, ensina de forma intencional e colabora para a aprendizagem. 
Durante os momentos de brincadeiras, o educador é capaz de avaliar a criança e ajustar seu planejamento. As intervenções realizadas durante a brincadeira, estimulam a criança a pensar, decidir, confrontar-se e resolver conflitos. O papel do educador é mediar a brincadeira, criar espaços e possibilidades para a criança se desenvolver, ou seja, é brincar junto auxiliando a criança. Brougère (2010, p. 111), contribui com essa função quando diz que

O educador pode, portanto, construir um ambiente que estimule a brincadeira em função dos resultados desejados. Não se tem certeza de que a criança vá agir, com esses materiais, como desejaríamos, mas aumentamos, assim, as chances de que ela o faça; num universo sem certezas, só podemos trabalhar com probabilidades.

Se antes a função do educador era somente de prover cuidados, hoje esse entendimento se amplia, colocando o educador em evidência juntamente como a criança. Seu trabalho se revela de grande importância, pois sem sua contribuição ativa dentro dos espaços da rotina infantil, a criança não conseguiria se desenvolver de forma integral. Ao passo que, o educador é peça chave para que essa aprendizagem aconteça. Fortuna (2011, p. 10), relata sobre essa atuação.

\footnotetext{
A atuação do educado infantil não deve restringir-se à observação e a oferta de brinquedos: ele intervém no brincar, não para apartar brigas ou para decidir quem fica com o quê, ou quem começa e quando termina, e sim para estimular, a atividade mental, social e psicomotora das crianças, com questionamentos e sugestões de encaminhamentos
}

Diante do que foi apresentado, fica claro entendermos o porquê a criança é considerada sujeito de direito e de tal maneira o brincar é restringido a atividade secundária dentro das práticas pedagógicas dos educadores.

A história mostrou os conflitos envolvidos para se chegar as concepções existente, de modo que os educadores necessitam conhecer esse percurso e se apropriar dessas concepções para que a criança se desenvolva de forma integral sem ferir seus direitos de viver uma infância presente.

\section{ALGUMAS CONSIDERAÇÕES}

Vimos que a concepção de criança e brincar se modificaram na história de acordo com os modelos de sociedade que iam surgindo. Até chegar ao atual conceito de 
criança como sujeito de direito, várias foram as discussões até serem consideradas então como são.

A necessidade das aberturas dos espaços de Educação Infantil ocorre pelo reflexo direto das transformações sociais impostos pelo sistema capitalista que estimulou a urbanização e modificou a organização familiar. que tinha a finalidade de guardar as crianças, empurrando para um debate sobre a regulamentação dessa etapa bem como o papel do educador de crianças pequenas.

Em relação ao brincar vimos que ele sempre esteve presente em diferentes tempos e contextos sociais que a criança estivesse inserida. Logo, só foi reconhecido como atividade inerente à criança a partir do XIX.

As leituras apontaram que elevar a criança à categoria de sujeito de direito foi necessário pela ausência de sua presença por muito tempo dentro da história da sociedade, onde a criança era confundida com um adulto recebendo quase sempre os mesmos tratamentos.

Essa posição de ser que tem direito contribuiu para marcar a criança como ser de especificidades diferenciando-se do adulto e a infância como fase mais importante do ser humano. Além disso, atribuir ao brincar fonte de desenvolvimento e aprendizagem e categoria própria da infância foi um marco para reconhecer o lugar da criança na sociedade.

Assim, os estudos mostraram que a atividade do brincar deve permear toda a Educação Infantil como forma não somente de garantir um direito essencial e fundamental, mas também de validar o desenvolvimento integral da criança, além de servir como base para toda proposta pedagógica.

Entretanto, mesmo com as afirmativas de um brincar como elemento de promoção de desenvolvimento infantil, muitos estudos apontaram que embora o brincar tivesse chegado a categoria de direito, muitos educadores ainda relutam em considerar e colocar essa atividade como eixo de sua prática, ferindo o direito da criança de brincar nos espaços escolares e aprender pela mediação dessa atividade.

Mesmo sendo muito claro o objetivo da Educação Infantil, que é o desenvolvimento pleno da criança sem a antecipação de conteúdos referentes ao ensino fundamental, os educadores ainda organizam suas rotinas tendo a alfabetização como referência, deixando o brincar para o segundo plano. 
Conhecer a evolução da criança e da infância é tarefa de todo educador da Educação Infantil, sob a justificativa de que ele possa romper com práticas tradicionais que limitam o desenvolvimento da criança restringindo a atividades do brincar, ampliando seu papel como mediador durante as brincadeiras, e ressignificando o brincar a partir de sua prática docente.

Desse modo, ampliar o tempo para o brincar, replanejar a rotina, disponibilizar materiais diversos, criar ambientes para que as brincadeiras possam fluir, são pistas possíveis e realizáveis que favorecem o brincar nos espaços infantis, melhorando assim as práticas das educadoras. Abrindo possibilidades para experiências mais criativas, dinâmicas, flexíveis, garantia dos direitos fundamentais, vivências com o meio e com o outro. Uma oportunidade que as educadoras têm de transgredir o mecânico, legitimando e potencializando as interações por meio do brincar infantil.

\section{REFERÊNCIAS}

BENJAMIN, W. (1984). Reflexões: a criança, o brinquedo, a educação. São Paulo: Summus.

BORBA, Ângela Meyer. A brincadeira como experiência de cultura. In:

CORSINO, Patrícia (org.) Educação infantil: cotidiano e políticas. Campinas, SP: Autores Associados, 2009. P. 69 a 78.

BRASIL. Constituição da República Federativa do Brasil, de 15 de novembro de 1988. Palácio do Planalto. Presidência da República. Disponível em:

<http://www.planalto.gov.br/ccivil_03/Constituicao/Constituicao.htm.> Acesso em: 12 dez. 2017.

BRASIL. Estatuto da Criança e do Adolescente. Lei n. 8.069 de 13 de julho de 1990. Disponível em <http://www.planalto.gov.br/ccivil_03/leis/L8069.htm>. Acesso em 01 de março de 2017.

BRASIL. Estatuto da Primeira Infância. Lei n. 13.257, de 08 de março de 2016.

Disponível em: <http://www.planalto.gov.br/ccivil_03/_ato2015-

2018/2016/lei/l13257.htm> Acesso em: 12 dez. 2017.

BRASIL. Lei no 4.024, de 20 de dezembro de 1961. Fixa as Diretrizes e Bases da

Educação Nacional. Disponível em: wwwp.fc.unesp.br/ lizanata/LDB\%204024-

61.pdf. Acessado em: 04/04/2022. 
BRASIL. Ministério da Educação. Base Nacional Comum Curricular. Brasília, 2018. BRASIL. Ministério da Educação. Secretaria de Educação Básica. Diretrizes curriculares nacionais para a educação infantil / Secretaria de Educação Básica. Brasília: MEC, SEB, 2010.

BRASIL. Ministério da Educação. Secretaria de Educação Básica. Política Nacional de Educação Infantil: pelos direitos das crianças de zero a seis anos à educação. Brasília, 2006a.

BRASIL. Ministério da Educação. Secretaria de Educação Fundamental. Referencial Curricular Nacional para a Educação Infantil. Brasília, 1998.

BRASIL. Lei no 9.394, de 20 de dezembro de 1996. Lei de Diretrizes e Bases da Educação Nacional. Brasília, DF: 20 de dezembro de 1996.

BROUGÈRE, Gilles. Que possibilidades tem a brincadeira? In: BROUGÈRE, Gilles. Brinquedo e Cultura. 8. ed. São Paulo: Cortez, 2010, p. 104-113.

CAMPOS, Maria Malta. Critérios para um atendimento em creches que respeite os direitos fundamentais das crianças - 6.ed. Brasília: MEC, SEB, 2009.

Declaração Universal dos Direitos da Criança. 1959. Disponível em <http://www.dhnet.org.br/direitos/sip/onu/c_a/lex41.htm>. Acesso em 25/2/2022. FONSECA, J. J. S. Metodologia da pesquisa científica. Fortaleza: UEC, 2002 FORTUNA, Tania Ramos. O lugar do brincar na educação Infantil. Pátio. Porto Alegre. 2002, v.7, p. 8-10, 2011.

FROEBEL, F. Pedagogics of the Kindergarten - or his ideas concerning the play and plaything of the child. HARRIS, W.T. (Ed). The international series. New York/London: D. Appleton and Company, 1912. vol 30.

KISHIMOTO, T. M. O jogo e a educação infantil. São Paulo: Pioneira, 1998. KISHIMOTO, Tizuko Mochila (org). Jogo, brinquedo,brincadeira e a educação. São Paulo: Cortez, 2011.

KRAMER, Sonia. A política do pré-escolar no Brasil: a arte do disfarce. 2. ed. Rio de Janeiro: Achiame, 1987.

KUHLMANN JR., M. Histórias da educação infantil brasileira. Revista Brasileira de Educação. Maio, nº 14. 2000.

KUHLMANN JR., M. Infância e educação infantil: uma abordagem histórica. Porto Alegre: Mediação. 2010. 
LEONTIEV, Alexis. Os princípios psicológicos da brincadeira pré-escolar. In.

Vygotsky, Lev S. (et al.). Linguagem, desenvolvimento e aprendizagem. 6.ed. São Paulo: Ícone, 2001a. p. 119-142.

MARCONI, M.A. \& LAKATOS, E. M. Técnicos de pesquisa planejamento e execução de pesquisa, amostragens e técnicas de pesquisas, elaboração, analise e interpretação de dados. $6^{\mathrm{a}}$ edição, São Paulo: Atlas, 2007.

ONU - ORGANIZAÇÃO DAS NAÇÕES UNIDAS. Declaração Universal dos

Direitos Humanos, 1948. Disponível em: <https://www.unicef.org/brazil/declaracaouniversal-dos-direitos-humanos>. Acesso em: 12 dez. 2021.

PEREIRA, Antonio. Pesquisa de intervenção em educação - Salvador: Eduneb, 2019.

PORTO, B. S.; CRUZ, S.H.V. Uma pirueta, duas piruetas...Bravo! Bravo! A importância do brinquedo na educação das crianças e de seus professores. In: CRUZ, S.H.V.; PETRALANDA, M. (Org.). Linguagem e educação da criança. Fortaleza: UFC,2004. P.213-231.

PRODANOV, Cleber Cristiano; FREITAS, Ernani Cesar de. Metodologia do trabalho científico [recurso eletrônico]: métodos e técnicas da pesquisa e do trabalho acadêmico - 2. ed. -Novo Hamburgo: Feevale, 2013.

ROUSSEAU, Jean-Jacques. Emílio ou Da Educação. São Paulo: Martins Fontes,2004. VYGOTSKY, L.S; LURIA, A.R. \& LEONTIEV, A.N. Linguagem, desenvolvimento e aprendizagem. São Paulo: Ícone: Editora da Universidade de São Paulo, 1998. WAJSKOP, Gisela. Brincar na pré-escola. 4ª ed. São Paulo: Cortez, 2001. WAJSKOP, Gisela. O brincar na educação infantil. Caderno de pesquisa. São Paulo. Nº92. Pág. 62-69. 1995. 